\title{
ESTUDIOS
}

\section{Una propuesta alternativa al Producto Interior Bruto como indicador de sostenibilidad y desarrollo bajo el prisma del pensamiento social cristiano'}

\author{
Ricardo Aguado y Jabier Martínez ${ }^{2}$
}

Resumen: Este trabajo examina la idoneidad del Producto Interior Bruto (PIB) per cápita y de otras medidas similares como indicadores de la sostenibilidad económica, ambiental y social de una economía nacional. Para ello se toman en consideración estudios recientes que han discutido sobre ello [Stiglitz et al. (2009), Fleaurbaey (2009) y CMEPSP (2009), por ejemplo]. Adicionalmente, los autores consideran un nuevo punto de partida: los principios del Pensamiento Social Cristiano. En concreto, los autores presentan indicadores complementarios al PIB para medir la sostenibilidad económica, social y ambiental, a la luz de las encíclicas papales (por ejemplo, Caritas in Veritate) y de las Congregaciones Generales 34 y 35 de la Compañía de Jesús.

Palabras clave: PIB, desarrollo sostenible, Pensamiento Social Cristiano.

Fecha de recepción: 19 de mayo de 2011 .

Fecha de aceptación definitiva: 5 de julio de 2011 .

\footnotetext{
${ }^{1}$ El presente texto es una versión revisada de la ponencia presentada por el prof. R. Aguado en el Coloquio de la Revista de Fomento Social, "Hacia una reforma del sistema económico", el día 20 de mayo de 2011. Los autores agradecemos las sugerencias realizadas por los evaluadores anónimos que han revisado el presente artículo.

${ }^{2}$ Deusto Business School-Universidad de Deusto, campus de Bilbao.
} 


\section{An alternative proposal to the GIP like indicator of sustainability and development under the prism of the Catholic social thought}

Abstract: This paper examines the suitability of the GDP per head and other related measures as indicators of the sustainability of a given national economy. In order to do so, the au-thors will take into account recent studies where this idea has already been discussed [Stiglitz et al. (2009), Fleaurbaey (2009) and CMEPSP (2009), for example]. Nonethe-less, the authors take here a new starting point: the principles of the Catholic Social Thought. In short, the authors will present complementary indicators to GDP in order to measure economic, social and environmental sustainability. In order to do so, Papal encyclicals (e.g., Caritas in Veritate) and documents from the General Congregations of the Society of Jesus (e.g., GC.34 and 35) are considered, among other documentation.

Key words: GDP, sustainable development, Catholic Social Thought.

\section{Une proposition alternative au PIB comme indicateur de viabilité et développement sous le regard de la Pensée Sociale-chrétienne}

Résumé: Ce document examine la pertinence comme indicateurs de la viabilité économique, environnementale et sociale d'une économie nationale du PIB per capita et $d^{\prime}$ 'autres grandeurs similaires. Pour cela, des études récentes qui ont travaillé sur la question seront pris en compte [Stiglitz et al. (2009), Fleaurbaey (2009) et CMEPSP (2009), par exemple]. Également, les auteurs tiendront compte d'un nouveau point de départ: les principes de la Pensée Sociale-chrétienne. En particulier, les auteurs présenteront des indicateurs complémentaires au PIB afin d'établir la viabilité économique, sociale et environnementale sous la référence des encycliques papales (par exemple, Caritas in Veritate) et des Congrégations Générales 34 et 35 de la Compagnie de Jésus.

Mots clés: PIB, développement durable, Pensée Sociale-chrétienne.

\section{Introducción}

El Producto Interior Bruto (PIB) es el principal indicador para medir el éxito y la evolución de una economía dada. Se ha convertido también en el indicador generalmente aceptado para realizar comparaciones internacionales entre economías nacionales. No obstante, la idea de utilizar el PIB como un indicador para medir el nivel de producción y, al mismo tiempo, el nivel de bienestar ha sido controvertida desde el momento en que se comenzó a utilizar. S. Kuznets en 1934 indicaba que difícilmente se podría inferir el bienestar de un país a partir de una medida de su producción. Posteriormente, en su trabajo seminal, NoRDAHUS y TOBIN (1973) 
estudiaron las relaciones entre crecimiento económico, por un lado, y bienestar, sostenibilidad ambiental y distribución de la renta, por el otro.

Recientemente, otros economistas han insistido en sus críticas acerca de la utilización del PIB como una medida del bienestar (MARTíneZ y SANTACOlOMA, 2005). FleaURBAEY (2009), por ejemplo, insiste en estas ideas: el PIB es un indicador pobre del bienestar social al ignorar las variaciones en la riqueza, los flujos internacionales de rentas, la producción de servicios de las familias, la destrucción del medio ambiente y otros muchos factores determinantes del bienestar, como la calidad de las relaciones sociales, la seguridad personal y económica, la salud y la longevidad.

Al igual que con el estudio del bienestar, otro concepto con el que se ha ligado al PIB que ha cobrado relevancia en los últimos años, y controversia, es la sostenibilidad. Debido a las consecuencias del crecimiento económico en el medio ambiente y en la sociedad, las Naciones Unidades (ONU) crearon en 1987 la Comisión Mundial sobre Desarrollo y Medio Ambiente (WCED, en inglés) también conocida como la Comisión Brundtland. El objetivo de esta comisión consistía en estudiar la sostenibilidad del desarrollo económico, basándose en la primera definición ampliamente aceptada de desarrollo sostenible: el desarrollo que asegura las necesidades de las generaciones presentes sin comprometer la posibilidad de que las generaciones futuras puedan asegurar las suyas propias (WCED, 1987). Más recientemente, la cumbre mundial sobre medio ambiente celebrada por las Naciones Unidas en 2005 afirmó la existencia de tres pilares interrelacionados que sostienen el concepto de desarrollo sostenible: desarrollo económico, desarrollo social y protección ambiental (ONU, 2005). En esta cumbre, la tecnología y la innovación fueron propuestas como los medios principales para resolver la aparente contradicción de pretender avanzar en los tres pilares al mismo tiempo. Por su parte, la iniciativa de los Objetivos de Desarrollo del Milenio, propuesta también de la ONU, puede ser entendida como un intento de hacer llegar los beneficios del desarrollo económico a todos los seres humanos en todos los países del planeta, dentro de los límites de la sostenibilidad (SANTACOLOMA y AgUADO, 2011).

La idea de lograr el máximo nivel de crecimiento económico presente compatible con el cuidado medioambiental ha contribuido a ligar el PIB con el concepto de sostenibilidad. El objetivo final sería garantizar que las generaciones futuras puedan disfrutar de igualdad de oportunidades en relación con las generaciones presentes para lograr crecimiento económico y bienestar (ONU, 2010).

El principal objetivo de este trabajo es analizar la idoneidad del uso del PIB como indicador de sostenibilidad en una economía nacional, identificando las principales 
características que una medida adecuada de sostenibilidad debería incorporar. Este análisis será efectuado de acuerdo con la literatura económica relevante y el Pensamiento Social Cristiano. Un segundo objetivo será el de medir la eficiencia de distintas economías nacionales a la hora de lograr un desarrollo sostenible, teniendo en cuenta las tres dimensiones de la sostenibilidad (social, ambiental y económica), con el fin último de construir una taxonomía de países que responda a las tres dimensiones mencionadas.

El artículo se desarrolla de la manera que se indica a continuación. En la sección 2 se discute la idoneidad de utilizar el PIB como un indicador adecuado para medir la sostenibilidad de acuerdo a la literatura económica relevante y al Pensamiento Social Cristiano. En la sección 3 se sugiere una serie adicional de indicadores, complementarios al PIB, para elaborar una medición más ajustada de la sostenibilidad. En la sección 4 se explica la metodología de este artículo. En la sección 5, se calcula la eficiencia de diferentes economías nacionales a la hora de lograr un desarrollo sostenible. Adicionalmente, se presenta una taxonomía de economías nacionales realizada a partir del contraste econométrico multivariante de esa eficiencia. Para realizar el contraste se utilizará el método no paramétrico denominado análisis envolvente de datos (DEA). El artículo termina con una sección de conclusiones y el apartado bibliográfico.

\section{Pensamiento Social Cristiano, PIB per cápita y sostenibilidad}

El Pensamiento Social Cristiano (PSC) se ha centrado tradicionalmente en el desarrollo económico y social, incluyendo cuestiones relacionadas con las condiciones de trabajo, la economía, los derechos humanos y las relaciones internacionales. A la luz de las crecientes preocupaciones medioambientales estamos siendo testigos de una progresiva integración de la sostenibilidad ambiental dentro del tejido del Pensamiento Social Cristiano (MCCARTHY, 2006).

Algunos aspectos del concepto amplio de sostenibilidad han sido considerados por el PSC en el pasado. Uno de los primeros y más conocidos ejemplos de analizar la cuestión social ha sido la encíclica Rerum Novarum (León XIII, 1891). En esta encíclica, la sostenibilidad social y política del sistema económico adquirieron la máxima importancia. En ella se discutían asuntos como la pobreza de las masas, la búsqueda de una solución a la miseria y estrecheces que presionan de manera tan injusta a la mayoría de la clase trabajadora y los derechos relativos y los deberes 
mutuos de los ricos y los pobres. Estas materias fueron consideradas cuarenta años más tarde en la encíclica Quadragesimo Anno (Pío XI, 1931). Treinta años más tarde, la encíclica Pacem in terris (Juan XXIII, 1963) se centró en el tema de la paz. La paz es contemplada como una nueva dimensión de la sostenibilidad de cualquier sistema político, económico y social. En esta encíclica, el Papa Juan XXIII afirma que cada ser humano tiene el derecho a la vida, a la integridad corporal, y a los medios necesarios para un correcto desarrollo de la vida. La encíclica continúa con una enumeración de esos medios: comida, vestido, cobijo, descanso, cuidado médico y, finalmente, los servicios sociales necesarios. El acento está puesto en la dimensión social de la sostenibilidad.

El concepto de desarrollo, incluyendo las dimensiones económica y social, fue de nuevo tomado en consideración cuatro años más tarde en la encíclica Populorum progessio (Pablo VI, 1967). El Papa Juan Pablo Il consideró la cuestión social de una manera explícita en al menos tres encíclicas: Laborens exercens, Sollicitudo rei socialis y Centessimus annus (Juan Pablo II, 1981, 1987 y 1991). Muchas de las ideas expresadas por León XIII encontraron eco en estas tres encíclicas.

La promoción de la justicia, manifestada en un cambio en el estilo de vida, en los modelos de producción y de consumo y en las estructuras de poder establecidas que gobiernan actualmente las sociedades es necesaria para ayudar a pueblos enteros que actualmente están excluidos o marginados para entrar en la esfera del desarrollo económico y humano (Juan Pablo II, 1991). El Papa Benedicto XVI escribió y publicó en 2009 la encíclica Caritas in veritate. Entre otros muchos aspectos, la encíclica aborda el desarrollo humano, la desigualdad, la pobreza, la justicia y el desarrollo económico. En este caso, se introduce la idea de la sostenibilidad no sólo en el sistema económico, sino también en las esferas social, política y ambiental (Benedicto XVI, 2009). La introducción de esta idea multidimensional de sostenibilidad refleja la aceptación que esta idea ha tenido en el Pensamiento Social Cristiano en los últimos años, incluso décadas. Los obispos canadienses, entre otros, han recogido la preocupación papal por la sostenibilidad de manera repetida (Conferencia Episcopal Católica de Canadá, 1995, 2003 y 2008), afirmando que la armonía ecológica no puede existir en un mundo de estructuras sociales injustas; como tampoco las diferencias sociales extremas imperantes a nivel mundial pueden tener como resultado la sostenibilidad ambiental (Conferencia Episcopal Católica de Canadá, 2003). La necesidad de estudiar de manera conjunta las tres dimensiones principales de la sostenibilidad (económica, social y ambiental) es mencionada en todos los ejemplos mencionados anteriormente. Tanto el Pensamiento Social Cristiano, en lo referente tanto al cuidado medio ambiental como a la ética empresarial, ha evolucionado en estos últimos años desarrollando 
una serie de principios que constituyen el PSC contemporáneo sobre el medio ambiente y la ética empresarial. Esos principios pueden condensarse en seis ideas principales (SIIECCHIA, 2004; BYRON, 2010):

(1) La vida y la dignidad humanas deben permanecer como prioridad de cualquier consideración económica, ambiental y social; (2) el servicio desinteresado es el modelo apropiado para el cuidado humano, ambiental y para el desarrollo económico; (3) las obligaciones hacia las generaciones futuras deben influir en la toma de decisiones en las áreas económica, social y medio ambiental; (4) considerando el principio de subsidiariedad, las decisiones económicas, ambientales y sociales deberían ser tomadas en el nivel apropiado; (5) el derecho a la propiedad privada y el mandato de usar la propiedad para el bien común deben ser respetados en las políticas económica, social y ambiental; (6) las preocupaciones por la sostenibilidad (económica, social y ambiental) son también preocupaciones de tipo moral que requieren de un replanteamiento de nuestra cultura económica basada en el consumo.

La encíclica Caritas in veritate incorpora un concepto de desarrollo sostenible holístico e integral, que incluye las dimensiones social, económica y ambiental. El desarrollo económico aparece ligado a la justicia, al bien común, a la fraternidad, a la libertad y al cuidado del medio ambiente. La idea de "desarrollo humano integral", que agrupa todas las dimensiones de la sostenibilidad, es uno de los puntos clave de la encíclica (BENEDICTO XVI, 2009 §21). Junto con el crecimiento económico, en la encíclica se señalan otros objetivos que deben ser promovidos, tales como el pleno empleo, la igualdad en el reparto de la renta, la cohesión social, el respeto por la democracia y por los sistemas de protección social (BENEDICTO XVI, 2009 §32, 35, 36). Las encíclicas papales y otras instituciones de la Iglesia Católica han estudiado el desarrollo desde una aproximación multidimensional, incluyendo el concepto de sostenibilidad. Una de estas instituciones ha sido la Compañía de Jesús. Con el objetivo de estudiar de manera sistemática esta contribución desde fechas recientes, nos referiremos a dos documentos de las dos últimas Congregaciones generales (CG) de la Compañía de Jesús: CG 34 y CG 35. La Congregación general 34 tuvo lugar en 1995. En la CG 34, la Compañía de Jesús reafirmó que la promoción de la justicia era uno de los puntos clave de su actividad apostólica. La sostenibilidad ambiental y la solidaridad intergeneracional tenían también gran importancia ya que

un uso sostenible y equitativo de los recursos mundiales es un elemento importante de justicia hacia todas las comunidades de nuestra aldea global, este uso también es un elemento de justicia hacia las generaciones futuras, que serán las que hereden el mundo que les dejamos. Una explotación sin escrúpulos de los recursos naturales y del medio 
ambiente degrada la calidad de vida, destruye culturas y hunde a los pobres en la miseria (CG 34, D.3 §9).

En el mismo documento, la Compañía de Jesús expresaba su preocupación por un tipo de desarrollo económico que tiene como uno de sus resultados no deseados la exclusión de

millones de personas de los beneficios de la sociedad. Los desempleados de larga duración, los jóvenes sin ninguna posibilidad de empleo, los niños de la calle explotados y abandonados, las personas mayores que viven solas sin protección social, ex-convictos, víctimas del abuso de las drogas y aquellos afligidos con SIDA -todos ellos están condenados a vidas de pobreza, marginación social y existencia precaria (CG 34, D.3 §15).

En 2008, la Compañía de Jesús se reunió en una nueva Congregación general, la CG 35. Esta CG efectuó una fuerte llamada a establecer unas relaciones adecuadas con el conjunto de la creación (Fernández Franco, 2011). En el Decreto 2, la Compañía reconoce la raíz global de los problemas relacionados con el desarrollo, el cuidado medio ambiental y la sostenibilidad, porque

la globalización, la tecnología y las preocupaciones por el medio ambiente han puesto a prueba nuestros límites tradicionales y han incrementado nuestra comprensión de que compartimos una responsabilidad común en el bienestar del mundo y en su desarrollo sostenible y fecundo (CG 35, D2 §20).

Siguiendo este pensamiento, el Decreto 3 analiza el rol de la globalización como una fuerza que da forma al desarrollo económico mundial. Los logros positivos y negativos de la globalización son subrayados en el propio decreto 3, cuando éste reconoce que mientras muchas personas pobres han visto mejorada su situación, la diferencia entre ricos y pobres dentro de las naciones y a través de las fronteras nacionales se ha incrementado (CG 35, D.3 §25). Siguiendo el pensamiento de Juan Pablo II, la CG 35 propone una globalización en solidaridad, una globalización sin marginación (CG 35, D.3 §30 y Juan Pablo II, 1998).

\section{Indicadores complementarios al PIB}

Como se ha mencionado en el apartado anterior, en el desarrollo económico, el bienestar social y todas las dimensiones de la sostenibilidad (principalmente la económica, la social y la ambiental) se encuentran interconectadas. Esta interconexión implica que, para apoyar el desarrollo en el largo plazo, es necesario actuar al mismo tiempo sobre las variables vinculadas al crecimiento y sobre las 
variables relacionadas con la sostenibilidad ${ }^{3}$. El primer paso en esta dirección es el de diseñar indicadores adecuados en el ámbito de la sostenibilidad y del desarrollo económico. El PIB puede ser un buen indicador para medir la evolución del valor de mercado de la producción de un determinado territorio, pero tiene importantes debilidades como indicador de sostenibilidad (como se ha explicado en la sección 2). A continuación señalaremos algunas de esas debilidades:

- No considera los aspectos inter-generacionales.

- No tiene en cuenta la distribución de la renta ni la marginación social.

- No mide el stock remanente de minerales y materias primas finitas.

- No toma en consideración el daño ambiental causado por el crecimiento económico.

Con el objetivo de conseguir una medida más exacta de desarrollo económico y sostenibilidad, el PIB debe ser complementado con otros indicadores que puedan ofrecer información sobre todas las dimensiones relevantes de la sostenibilidad que no estén consideradas por el PIB. Se ha realizado un número importante de estudios para obtener indicadores adicionales de sostenibilidad (distintos al PIB o a la tasa de crecimiento del PIB), de carácter holístico, tanto en valor absoluto como en valores per cápita. En la Tabla 1 recogemos de MARTínez (2010) una clasificación de los indicadores de sostenibilidad, que se podría completar con los acercamientos alternativos a la medición del crecimiento: generales, que tratan de reflejar el estado de progreso, la riqueza y/o el bienestar de una economía concreta; y los específicos, que se centran en algún aspecto concreto (del progreso, riqueza y/o bienestar) (MARTínEZ, 2011)4. En este artículo proponemos una aproximación distinta. En primer lugar procedemos a seleccionar una serie de indicadores complementarios al PIB, de acuerdo a los planteamientos expresados en las secciones 1 y 2 ; una vez que esos indicadores hayan sido escogidos y justificados, se planteará la sección de metodología, donde se explicarán los procedimientos y técnicas econométricas que serán seguidas en el artículo. De acuerdo

\footnotetext{
${ }^{3}$ Un trabajo que plantea y revisa una visión alternativa de crecimiento económico, más centrada en la persona (en lugar de la visión tradicional centrada en el mercado) y su relación con el desarrollo y desigualdad se puede encontrar en MARTíneZ, 2010.

${ }^{4}$ El Índice de Desarrollo Humano de las Naciones Unidas (IDH), así como el Índice de Pobreza Multidimensional del Programa de Naciones Unidas para el Desarrollo (PNUD) serían ejemplos de los índices compuestos, mientras que los Indicadores locales de la Agenda 21 de Medio Ambiente de las Naciones Unidas (PNUMD) se podrían encuadrar dentro de la tipología "tablero de Indicadores".
} 
a lo argumentado en las secciones previas, la sostenibilidad cuenta, al menos, con tres dimensiones diferenciadas: la económica, la social y la ambiental. El PIB puede ser un indicador adecuado para medir si el valor de mercado "per cápita" de los bienes y servicios producidos en una economía nacional está creciendo o no. En ese caso, el PIB podría ser un indicador para medir el progreso material de una sociedad (vinculado a la sostenibilidad económica), considerando el total de las personas que conforman esa sociedad. En cualquier caso, sería necesario complementar esa dimensión con la social y la ambiental.

Desde el punto de vista social sería conveniente que el crecimiento económico (reflejado en el indicador PIB per cápita) estuviera distribuido de manera equitativa entre el conjunto de la población. De esta manera toda la ciudadanía podría beneficiarse del proceso de crecimiento económico. El primer indicador que vamos a utilizar para medir la sostenibilidad social es la tasa de pobreza infantil, ya que en cualquier país los niños son la parte más vulnerable de la población. El coeficiente de Gini, a partir del cálculo de la disparidad en la distribución de la renta, nos indica, en cierto modo, el nivel de equidad en una sociedad, y será el segundo indicador que utilizamos para medir la sostenibilidad social. El tercer indicador para medir la sostenibilidad social es la tasa de desempleo. Un sistema económico generador de elevadas tasas de desempleo será inviable desde el punto de vista social, pues el descontento social creado, en sociedades democráticas al menos, forzaría por la vía electoral una reforma forzosa del sistema. Por último analizamos el porcentaje de personas con educación terciaria como último indicador para la dimensión de la sostenibilidad.

Tanto el crecimiento económico como la sostenibilidad social necesitan ser combinadas con la sostenibilidad ambiental para garantizar un mejor futuro a las próximas generaciones. En relación con la sostenibilidad ambiental vamos a utilizar dos indicadores: la tasa de reciclaje de residuos y las emisiones de efecto invernadero por unidad de PIB. Este último indicador considera la cantidad de $\mathrm{CO}_{2}$ necesaria para producir un euro de PIB. Las economías capaces de minimizar este valor están reduciendo su vulnerabilidad ambiental y se están encaminando hacia actividades económicas que no requieren de la generación de emisiones de $\mathrm{CO}_{2}$ para producir valor. Se trata, entonces, de economías que están en proceso de incrementar su sostenibilidad desde el punto de vista ambiental. En ese mismo caso se encontrarían aquellas economías nacionales capaces de incrementar su tasa de reciclaje de residuos. Estas economías estarían mostrando su capacidad para desvincular el crecimiento económico y la sostenibilidad social de la emisión de gases de efecto invernadero y la acumulación de materiales de desecho. 


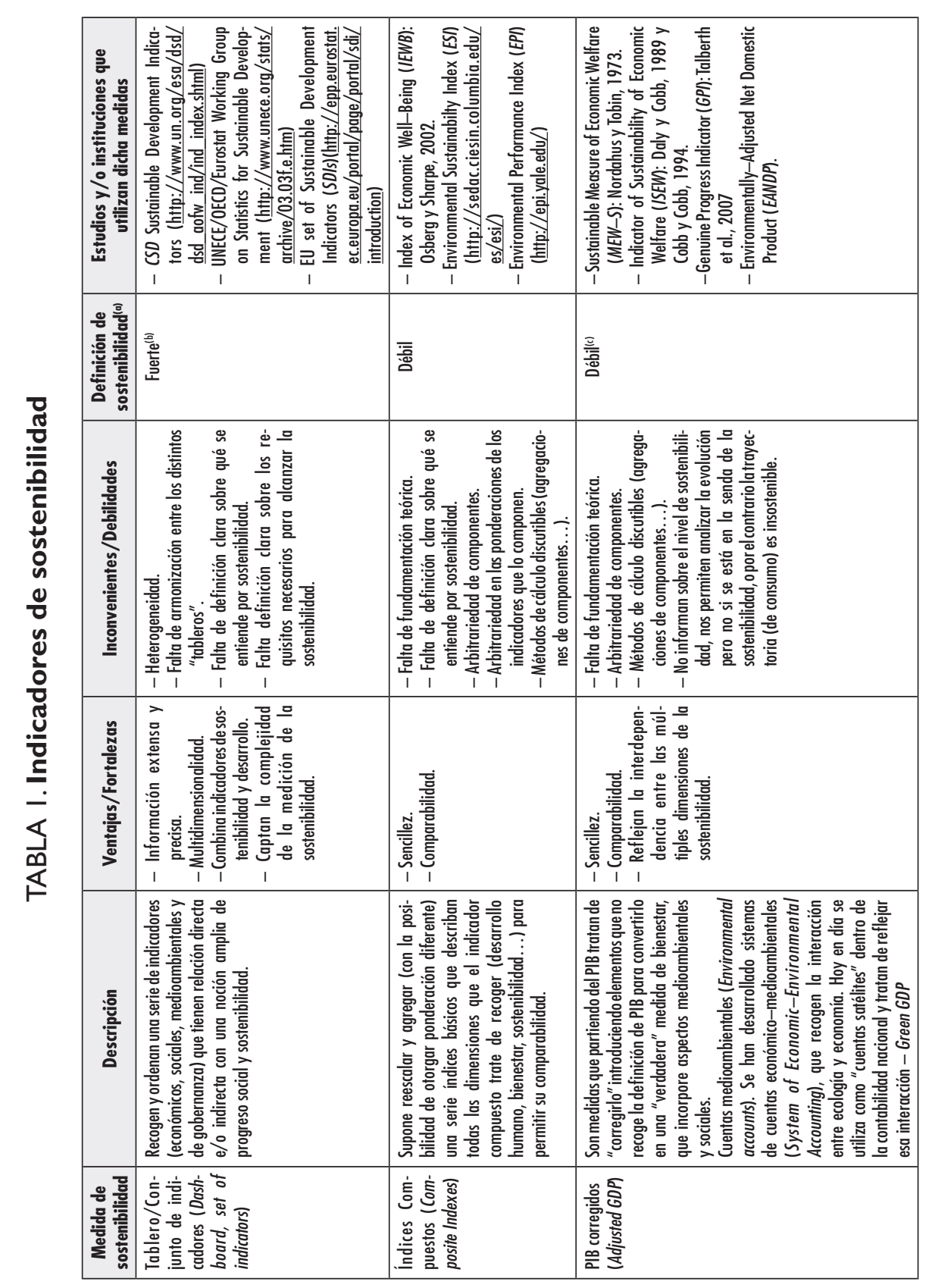

228

ESTUDIOS 

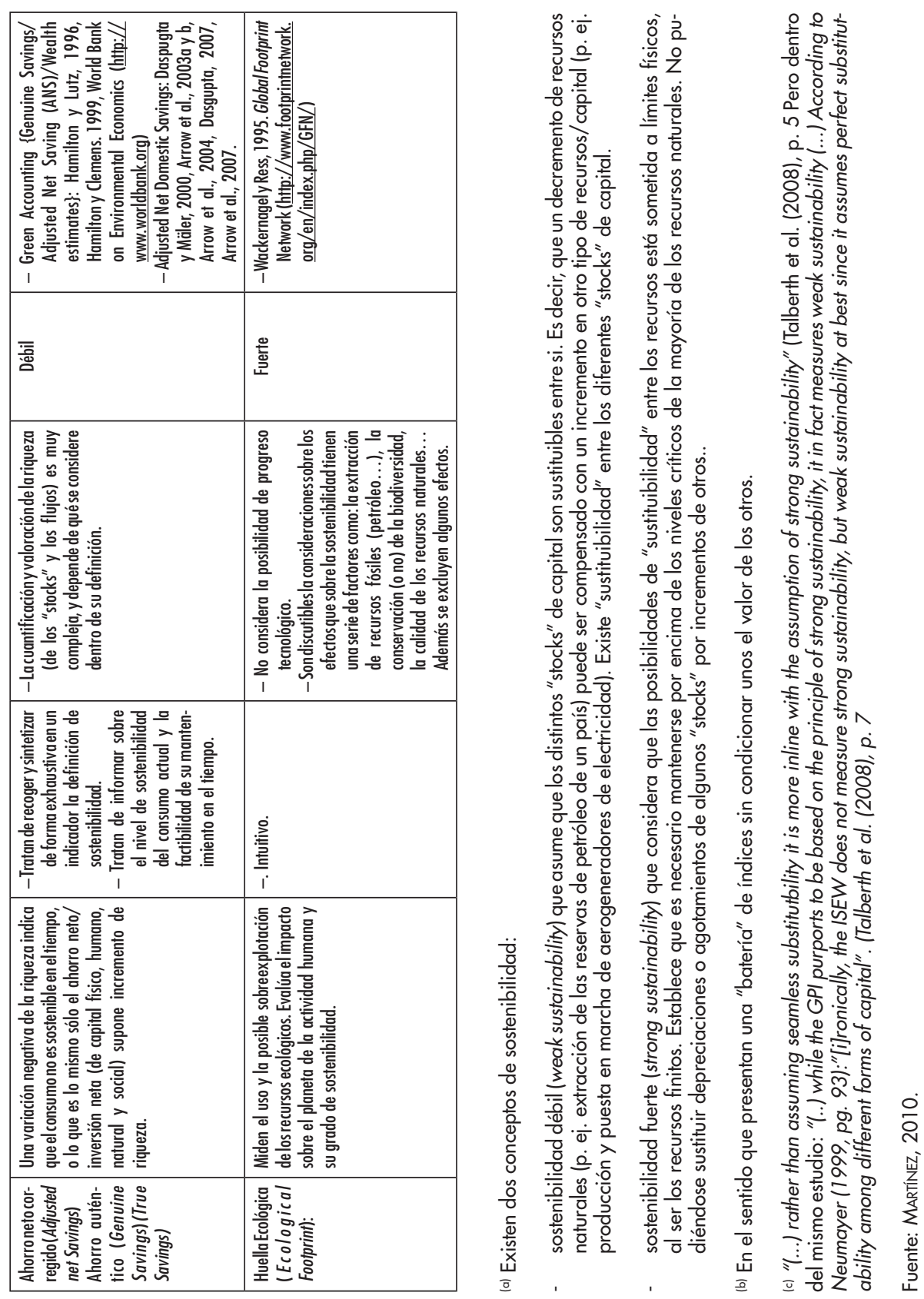

Revista de Fomento Social 66 (20II) 
Una economía nacional que muestre resultados positivos en las tres dimensiones mencionadas constituiría una economía sostenible de manera integral porque sería competitiva en los mercados internacionales y ofrecería mejores condiciones materiales a sus ciudadanos (sostenibilidad económica), tendría una muy baja tasa de pobreza en lo que respecta a la parte más vulnerable de la población (niños), la riqueza estaría repartida de manera equitativa entre la población, dedicaría una parte importante de su riqueza nacional a la educación (sostenibilidad social) y, finalmente, esa economía sería capaz de minimizar las emisiones de efecto invernadero por unidad de "output" producida, a la vez que incrementaría la tasa de reciclaje de residuos (sostenibilidad ambiental).

\section{Metodología}

Mediante el análisis econométrico medimos la eficiencia de una economía dada a la hora de lograr el desarrollo sostenible. La noción de productividad que habitualmente se maneja en economía se refiere a la cantidad de recursos ("inputs") que se necesitan para producir un/os producto/s ("outputs"). El análisis de la productividad nos lleva al estudio de la eficiencia: la combinación óptima de recursos para obtener dichos productos. En el estudio de la eficiencia se han desarrollado dos grandes metodologías: los métodos paramétricos, como el análisis de frontera estocástico ("stochastic frontier analysis" - SFA), que utilizan métodos de estadística multivariante para analizar las variaciones en la producción o costes entre distintas organizaciones que desarrollan una misma actividad (entidades financieras, hospitales...); y los métodos no paramétricos, como el análisis envolvente de datos ("data envelopment analysis" - DEA) que trata de medir la eficiencia de dichas entidades (que desarrollan una misma actividad) estimando el nivel óptimo de producto en función de la cantidad y combinación de los recursos de que dispone (SMITH Y STREET, 2005). En nuestro caso hemos elegido el análisis envolvente de datos $(D E A)^{5}$ al ser nuestro objetivo final establecer una tipología de países en base a unos "inputs" y unos "outputs" relacionados con la sostenibilidad en sus múltiples dimensiones. Para este propósito se adecúa mejor la metodología DEA que los métodos paramétricos. Además evitamos tener que establecer una forma funcional sobre los datos, ni asunciones sobre la distribución que subyacen a los mismos, cosa que tendríamos que hacer en caso de utilizar métodos paramétricos.

\footnotetext{
${ }^{5}$ Una exposición exhaustiva de esta metodología se puede encontrar en Cooper et al., 2000 y 2004 , Thanassoulis, 2001 y COELI ET AL., 1998.
} 
El desarrollo de esta metodología arranca con el artículo de ChARNES et AL. (1978), a partir del trabajo pionero de FARELL (1957) y su noción de que una organización que utiliza menos recursos para producir la misma cantidad de producto, se puede considerar más eficiente. Básicamente esta metodología parte de la consideración de que se puede calcular el "ratio" de eficiencia de una entidad, empresas, país... (DMU - "Decisión Making Units"), como el cociente entre suma ponderada de los "outputs" que produce y la suma ponderada de los "inputs" que utiliza. En el estudio de la eficiencia, para cada DMU esas ponderaciones se obtienen resolviendo un problema de optimización lineal consistente en la maximización de dicho cociente sujeto a la restricción de que los cocientes (de "outputs" entre "inputs" ponderados) para el resto de DMU (de la muestra analizada) son menores o iguales a 1. Repetir el análisis para cada DMU nos permite construir una frontera eficiente integrada por aquellas entidades (DMU) más eficientes (que utilizan menor cantidad de "inputs" por unidad de "output" o producen mayor "output" por unidad de "input"). Las unidades económicas situadas en la frontera tendrán un índice de eficiencia del $100 \%$ teniendo el resto una eficiencia relativa menor que ese $100 \%$, en comparación con alguna de las eficientes (ver figura 1). Por lo tanto, el análisis DEA nos permite construir esa frontera de eficiencia.

\section{FIGURA I. Frontera eficiente}

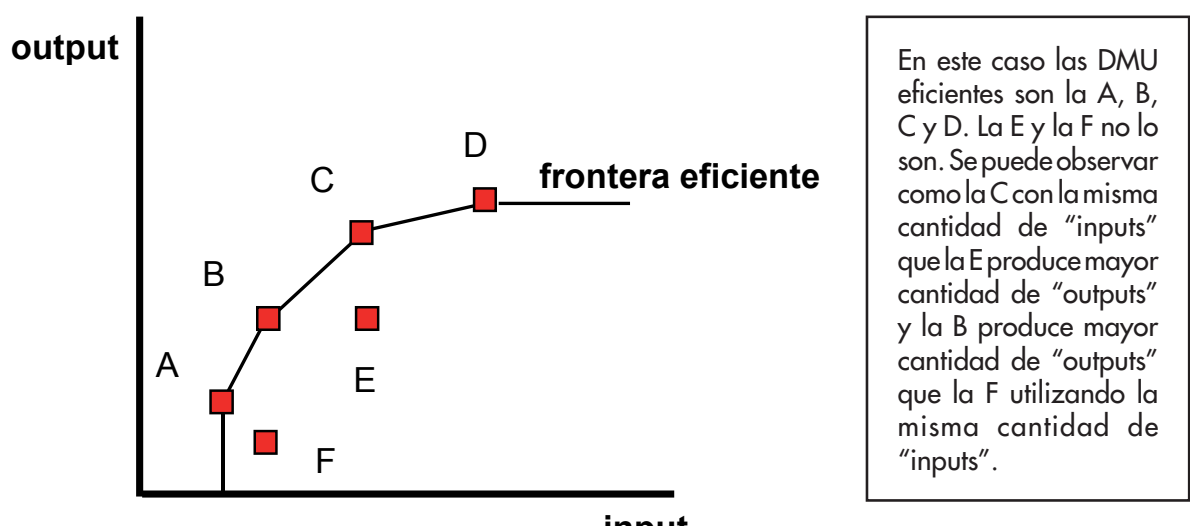

input

Los modelos DEA se pueden dividir, a grandes rasgos, en función de: (i) el enfoque del modelo [maximización de la producción ("outputs") con los recursos existentes ("inputs") -modelos orientados a los "outputs" ("output-oriented") o minimización de los recursos ("inputs") para una producción dada ("outputs")- modelos orien- 
tados a los "inputs" ("input-oriented")] y (ii) tipo de rendimientos [rendimientos constantes a escala (modelo conocido como CCR) recogido en CHARNES et al., 1978 o rendimientos variables a escala (modelo conocido como BCC) propuesto por BANKER et al.,1984].

El modelo que nosotros construimos es un modelo tipo CCR (con rendimientos constantes a escala) orientado al "output". Las razones de esta elección se fundamentan en que nos vamos a fijar primordialmente en los resultados ("outputs") de las DMU (países) con relación a los indicadores que presentamos más adelante (modelo orientado a los "outputs") y que asumimos que no se generan (des)economías de escala con una mayor o menor utilización de recursos (rendimientos constantes a escala). La modelización propuesta se puede representar en el siguiente modelo de optimización lineal:

$$
\begin{aligned}
& \min \underset{j=1}{\stackrel{r}{\dagger}} \mathfrak{u}_{j} x_{j k}
\end{aligned}
$$

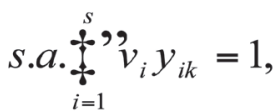

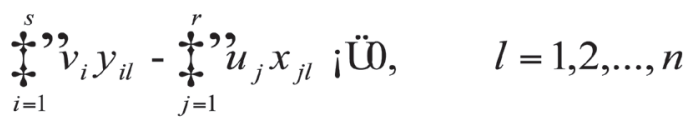

$$
\begin{aligned}
& u_{j} \text { i } \dot{Y} \varepsilon>0, \quad j=1,2 \ldots, r \\
& v_{i} \text { iÝ }{ }^{\prime}>0, \quad i=1,2 \ldots, s
\end{aligned}
$$

O su dual:

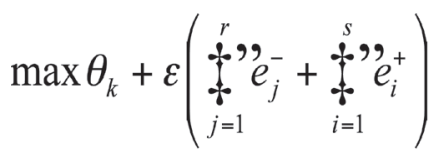

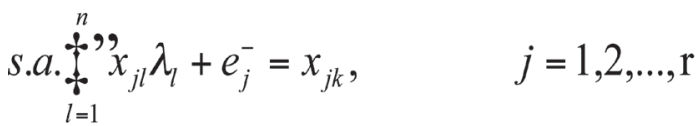

$$
\begin{aligned}
& \stackrel{n}{\dagger} \stackrel{n}{\dagger}^{\prime} y_{i l} \lambda_{l}-e_{i}^{+}=\theta_{k} y_{i k}, \quad i=1,2, \ldots, \mathrm{S} \\
& l=1 \\
& \lambda_{l} \text { ¡Ý́ }, \quad l=1,2 \ldots, n
\end{aligned}
$$


Asumiendo que existen $r$ "inputs" diferentes $(j=1,2, \ldots, r)$, s "outputs" diferentes $(i=1,2, \ldots, s)$ y $n \mathrm{DMU}(I=1,2, \ldots n)^{6}$. $x_{j k}$ es la cantidad de "input" $i$ de la DMU $k, y_{i k}$ la cantidad de "output" $i$ de la DMU $k, u_{j}$ la ponderación (peso) asignada al "input" iy $v_{i}$ la ponderación asignada al "output" i. Como se ha comentado, para medir la eficiencia de cada DMU el modelo ha de ser implementado para cada una de las $n$ DMU. $\varepsilon$ es una constante infinitesimal que evita que alguno de los "inputs" (o "outputs") tomen valor (su ponderación) cero. Así en el dual $\theta_{k}$ es el nivel de eficiencia de la unidad de decisión analizada $\left(D M U_{k}\right)$ y $\lambda_{k}$ son los parámetros a partir de los que se construye el grupo unidades eficientes que se toman como referencia para la unidad objeto de análisis. La solución del programa nos indica que la unidad evaluada es eficiente al cien por cien, si $1 \theta_{k}=1$, siendo ineficiente en caso contrario, $\theta_{k}<1$.

En la figura 2 se señalan los pasos metodológicos seguidos en la confección de este estudio.

- En primer lugar se ha procedido a seleccionar las variables de "input" y "output" para poder realizar una medición de las tres dimensiones de la sostenibilidad (económica, social y ambiental), en base a las recomendaciones de la literatura repasada en las secciones previas.

- En segundo lugar, se han recogido los datos de las variables elegidas correspondientes a los 29 países de la OCDE para los que existían datos disponibles en todas las variables (el número actual de miembros totales de la OCDE es de 34 países).

- En tercer lugar, se ha medido la eficiencia los 29 países analizados utilizando la herramienta estadística análisis envolvente de datos (DEA).

- Por último, se ha procedido a realizar un ejercicio de "clusterización" de los 29 países analizados, de acuerdo a los resultados obtenidos en las fases de análisis anteriores. De esta "clusterización" se obtiene como resultado una taxonomía de países basada en la eficiencia a la hora de obtener un desarrollo sostenible.

\footnotetext{
${ }^{6}$ En nuestro caso, $i=3$ ( 3 inputs, Educación, Desempleo y Tasa de reciclado de residuos); $i=4$ (4 outputs, PIB per cápita, Emisiones $\mathrm{CO}_{2}$ por unidad de PIB, Inequidad y Pobreza infantil); $\mathrm{Y} l=29$ (países de la OCDE para los que existen datos).
} 
FIGURA 2. Fases de la metodología de investigación

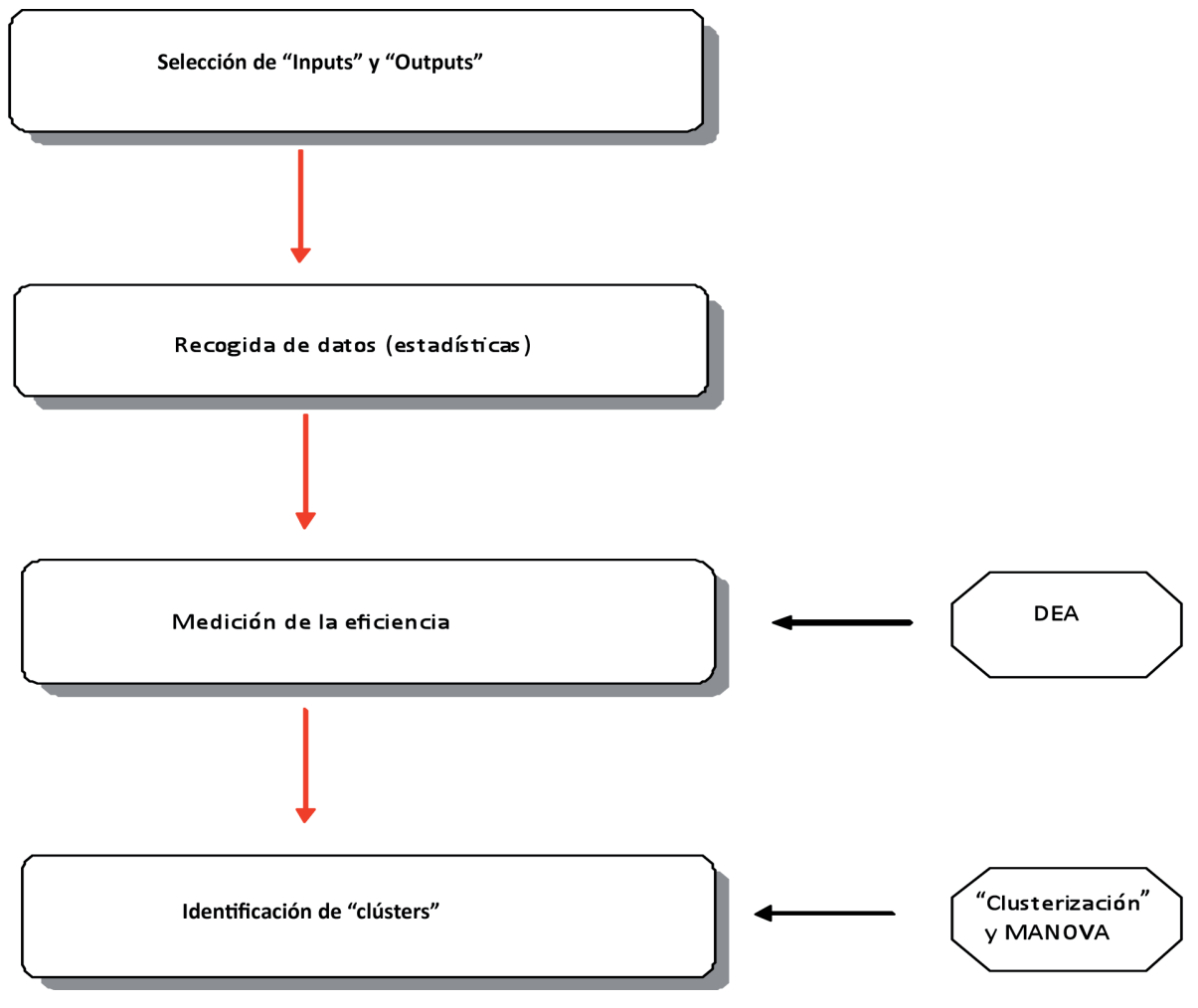

Fuente: LEE y PARK, 2005.

Elaboración propia.

A la hora de construir los modelos de eficiencia se han seleccionado tres variables de "input" y cuatro variables de "output". En la tabla 2 se recogen las variables escogidas, una descripción detallada de las mismas, las unidades de medida y el periodo para el cual han sido calculadas. El "output" que se trata de medir es el desarrollo sostenible en sus tres dimensiones: económico, social y ambiental. Como indicadores de "input" hemos utilizado desempleo, el porcentaje de personas

7 Este número de variables cumple con la la regla práctica que CoOPER, et al. (2000) aconsejan tener en cuenta al aplicar un modelo DEA, esto es: $n \geq \max \{r \times s, 3(r+s)\}$, donde $n$ es el número de unidades analizadas (DMUs), $r$ el número de "inputs" y $s$ el número de "outputs". En nuestro caso $29>\max \{4$ $\times 3,3(4+3)\}=21$. 
con educación terciaria y la tasa de reciclaje de residuos. De acuerdo con esta metodología, el objetivo es usar la mínima cantidad de "inputs" para lograr la máxima cantidad de "output". Por eso, a la hora de medir la cantidad de "inputs" utilizaremos 100\% - el nivel de educación terciaria, en lugar de utilizar el nivel de educación terciaria. Realizaremos el mismo procedimiento con la tasa de reciclaje de residuos. En relación a los "outputs", el objetivo consistirá en maximizar los indicadores considerados. Este es el caso del PIB per cápita, por ejemplo. Sin embargo, nuestro objetivo será el de maximizar la equidad (no la inequidad), y por esa razón maximizaremos el indicador 1- coeficiente de Gini (en lugar de maximizar el coeficiente de Gini). Este coeficiente varía entre 0 (equidistribución de la renta) y 1 (máxima desigualdad en la distribución de la renta). Una situación análoga ocurre con los indicadores de pobreza infantil y emisiones de $\mathrm{CO}_{2}$. Nuestro objetivo será maximizar $100 \%$ - tasa de pobreza (lo contrario a la pobreza) y $100 \%$ - emisiones de $\mathrm{CO}_{2}$ (lo contrario a maximizar las emisiones de $\mathrm{CO}_{2}$ ).

\section{TABLA 2. Variables “Input" y "Output”}

\begin{tabular}{|c|c|c|c|c|c|}
\hline Tipo & Variable & Descripción & Medida & Unidad & Año \\
\hline \multirow{3}{*}{ "Input" } & Educación & $\begin{array}{l}\text { Porcentaje de personas con estu- } \\
\text { dios terciarios en el grupo de edad } \\
24-65\end{array}$ & $100 \%-\%$ & Porcentaje & 2000 \\
\hline & Desempleo & $\begin{array}{l}\text { Tasa de desempleo armonizada } \\
\text { (TDH) }\end{array}$ & $\%$ & Porcentaje & 2005 \\
\hline & $\begin{array}{l}\text { Tasa de } \\
\text { reciclaje de } \\
\text { residuos }\end{array}$ & $\begin{array}{l}\text { Tasa de reciclaje de residuos (\% sobre } \\
\text { el consumo aparente) }\end{array}$ & $100 \%-\%$ & Porcentaje & 2005 \\
\hline \multirow{4}{*}{ “Output” } & PIBpc & PIB per cápita & $\begin{array}{l}\text { US \$ / } \\
\text { Población }\end{array}$ & $\begin{array}{l}\text { US \$ "per } \\
\text { cápita" }\end{array}$ & 2005 \\
\hline & $\begin{array}{l}\text { Emisiones } \\
\mathrm{CO}_{2} \text { por uni- } \\
\text { dad de PIB }\end{array}$ & $\begin{array}{l}\text { Emisiones de } \mathrm{CO}_{2} \text { procedentes de } \\
\text { combustión de fuel por unidad de } \\
\text { PIB }\end{array}$ & $\begin{array}{l}1-(\text { toneladas / } \\
000,000 \text { US } \$ \text { ) }\end{array}$ & $\begin{array}{l}\text { toneladas / } \\
\text { millones US \$ }\end{array}$ & 2005 \\
\hline & Desigualdad & $\begin{array}{l}\text { Coeficiente de Gini (después de } \\
\text { impuestos) }\end{array}$ & $\begin{array}{l}1-\text { coefi- } \\
\text { ciente Gini }\end{array}$ & [0-1] & $\begin{array}{l}\text { med. } \\
2000\end{array}$ \\
\hline & Pobreza & $\begin{array}{l}\text { Proporción de hogares con niños que } \\
\text { viven con un ingreso equivalente infe- } \\
\text { rior al } 50 \% \text { de la renta nacional media } \\
\text { de cada país para el año } 2005\end{array}$ & $100 \%-\%$ & Porcentaje & $\begin{array}{l}\text { med. } \\
2000\end{array}$ \\
\hline
\end{tabular}

Elaboración propia con base en datos de la OCDE. 
Como "outputs" tomaremos en consideración indicadores correspondientes a las tres dimensiones de la sostenibilidad. Con el PIB "per cápita" recogemos información sobre la parte económica de la sostenibilidad; con las emisiones de $\mathrm{CO}_{2}$, sobre la parte ambiental; y con la pobreza y la desigualdad, sobre la parte social ${ }^{8}$.

En la tabla 3 se muestran todos los modelos DEA posibles. En el modelo básico se toman en consideración todos los "inputs" y "outputs". En el modelo orientado a la producción hemos considerado todos los "inputs" y nos hemos centrado en la maximización de un único "output", el PIB "per cápita". En el modelo orientado a la protección ambiental, el objetivo es la minimización de todos los "inputs" y la maximización del indicador 1 - emisiones de $\mathrm{CO}_{2}$ (de hecho, minimizar las emisiones de $\mathrm{CO}_{2}$ ). En el modelo orientado a la equidad, el objetivo es la minimización del uso de "inputs" y la maximización de la equidad en la distribución de la renta entre los ciudadanos. En el último modelo, el propósito es la minimización del uso de "inputs", a la vez que se minimiza la pobreza a nivel social.

TABLA 3. Modelos de eficiencia DEA

\begin{tabular}{|c|c|c|c|c|c|c|c|}
\hline \multirow[b]{2}{*}{ MODELO DEA } & \multicolumn{3}{|c|}{ "Input" } & \multicolumn{4}{|c|}{ "Output" } \\
\hline & Educación & Desempleo & $\begin{array}{l}\text { Tasa reciclaje } \\
\text { de residuos }\end{array}$ & PIBpc & $\begin{array}{l}\text { Emisiones CO2 } \\
\text { por unidad PIB }\end{array}$ & Desigualdad & Pobreza \\
\hline Modelo básico & O & O & $\mathrm{O}$ & O & 0 & O & 0 \\
\hline $\begin{array}{l}\text { Eficiencia orientada } \\
\text { a la producción }\end{array}$ & $\mathrm{O}$ & $\mathrm{O}$ & $\mathrm{O}$ & O & & & \\
\hline $\begin{array}{l}\text { Eficiencia orientada } \\
\text { a la sostenibilidad } \\
\text { ambiental }\end{array}$ & $\mathrm{O}$ & $\mathrm{O}$ & $\mathrm{O}$ & & $\mathrm{O}$ & & \\
\hline $\begin{array}{l}\text { Eficiencia orientada } \\
\text { a la equidad }\end{array}$ & $\mathrm{O}$ & $\mathrm{O}$ & $\mathrm{O}$ & & & $\mathrm{O}$ & \\
\hline $\begin{array}{l}\text { Eficiencia orientada } \\
\text { contra la pobreza }\end{array}$ & $\mathrm{O}$ & $\mathrm{O}$ & O & & & & $\mathrm{O}$ \\
\hline
\end{tabular}

Elaboración propia.

\footnotetext{
${ }^{8}$ Podrían considerarse otros indicadores diferentes a los seleccionados en este análisis. Sin embargo, algunos de ellos podrían llevar a conclusiones erróneas. Si utilizáramos como indicador el consumo de energía "per cápita", un país en vías de desarrollo podría aparecer como muy eficiente debido a un bajo nivel de consumo de energía "per cápita". La razón de ese bajo consumo podría no ser el logro de la eficiencia energética, sino una economía poco desarrollada. Por esta razón nos hemos concentrado en indicadores significativos, disponibles para el mayor número posible de países y libres de posibles malinterpretaciones en el análisis de los resultados.
} 
En la tabla 4 se muestran los resultados de los distintos modelos mencionados. Los resultados iguales a 1 muestran la máxima eficiencia en la relación entre "inputs" y "outputs". Por el contrario, los resultados cercanos a cero indican muy bajos niveles de eficiencia. Norvega sería el ejemplo de máxima eficiencia. En todos los modelos considerados, Norvega obtiene el máximo nivel de eficiencia posible. Esto significa que, a igualdad de "inputs", Noruega obtendría siempre los mejores resultados en relación con el resto de países. Otros países, como por ejemplo el Reino Unido, no obtienen la máxima eficiencia. Esto significa que esos países, utilizando la misma cantidad de "inputs", podrían obtener mejores resultados (más PIB "per cápita", menos emisiones de $\mathrm{CO}_{2}$, menos desigualdad en el reparto de la renta y/o menos pobreza).

TABLA 4. Resultados de los modelos

\begin{tabular}{|l|l|c|c|c|c|c|}
\hline \multicolumn{2}{|c|}{ DMU (país) } & $\begin{array}{c}\text { Modelo } \\
\text { básico }\end{array}$ & $\begin{array}{c}\text { Eficiencia } \\
\text { orientada } \\
\text { a la pro- } \\
\text { ducción }\end{array}$ & $\begin{array}{c}\text { Eficiencia } \\
\text { orientada a la } \\
\text { sostenibilidad } \\
\text { ambiental }\end{array}$ & $\begin{array}{c}\text { Eficiencia } \\
\text { orienta- } \\
\text { da a la } \\
\text { equidad }\end{array}$ & $\begin{array}{c}\text { Eficiencia } \\
\text { contra la } \\
\text { pobreza }\end{array}$ \\
\hline AUS & Australia & 0.93 & 0.76 & 0.48 & 0.92 & 0.91 \\
AUT & Austria & 0.89 & 0.72 & 0.74 & 0.88 & 0.89 \\
\hline BEL & Bélgica & 0.90 & 0.71 & 0.74 & 0.90 & 0.88 \\
\hline CAN & Canadá & 1.00 & 0.86 & 0.62 & 1.00 & 1.00 \\
CZE & Rep. Checa & 0.76 & 0.36 & 0.35 & 0.76 & 0.73 \\
\hline DNK & Dinamarca & 1.00 & 0.74 & 0.86 & 1.00 & 0.99 \\
\hline FIN & Finlandia & 1.00 & 0.77 & 0.79 & 0.97 & 1.00 \\
FRA & Francia & 0.86 & 0.60 & 0.84 & 0.83 & 0.84 \\
\hline DEU & Alemania & 0.88 & 0.71 & 0.74 & 0.88 & 0.85 \\
\hline GRC & Grecia & 0.75 & 0.45 & 0.63 & 0.73 & 0.74 \\
HUN & Hungría & 0.78 & 0.30 & 0.64 & 0.77 & 0.78 \\
\hline ISL & Islandia & 1.00 & 1.00 & 1.00 & 1.00 & 1.00 \\
\hline IRL & Irlanda & 1.00 & 1.00 & 0.98 & 1.00 & 1.00 \\
\hline ITA & Italia & 0.69 & 0.51 & 0.68 & 0.67 & 0.68 \\
\hline JPN & Japón & 0.99 & 0.74 & 0.87 & 0.99 & 0.97 \\
\hline KOR & Corea & 1.00 & 0.63 & 0.71 & 1.00 & 1.00 \\
\hline MEX & México & 0.74 & 0.26 & 0.72 & 0.64 & 0.74 \\
\hline NLD & Holanda & 0.95 & 0.78 & 0.75 & 0.95 & 0.90 \\
\hline NZL & N. Zelanda & 0.99 & 0.71 & 0.87 & 0.98 & 0.99 \\
NOR & Noruega & 1.00 & 1.00 & 1.00 & 1.00 & 1.00 \\
\hline POL & Polonia & 0.63 & 0.24 & 0.36 & 0.63 & 0.63 \\
\hline
\end{tabular}




\begin{tabular}{|l|l|c|c|c|c|c|}
\hline \multicolumn{2}{|c|}{ DMU (país) } & $\begin{array}{c}\text { Modelo } \\
\text { básico }\end{array}$ & $\begin{array}{c}\text { Eficiencia } \\
\text { orientada } \\
\text { a la pro- } \\
\text { ducción }\end{array}$ & $\begin{array}{c}\text { Eficiencia } \\
\text { orientada a la } \\
\text { sostenibilidad } \\
\text { ambiental }\end{array}$ & $\begin{array}{c}\text { Eficiencia } \\
\text { orienta- } \\
\text { da a la } \\
\text { equidad }\end{array}$ & $\begin{array}{c}\text { Eficiencia } \\
\text { contra la } \\
\text { pobreza }\end{array}$ \\
\hline PRT & Portugal & 0.68 & 0.35 & 0.64 & 0.63 & 0.67 \\
SVK & Eslovaquia & 0.73 & 0.28 & 0.47 & 0.73 & 0.70 \\
\hline ESP & España & 0.79 & 0.53 & 0.73 & 0.79 & 0.76 \\
\hline SWE & Suecia & 1.00 & 0.88 & 1.00 & 1.00 & 1.00 \\
CHE & Suiza & 1.00 & 0.92 & 1.00 & 1.00 & 1.00 \\
\hline TUR & Turquía & 0.66 & 0.20 & 0.66 & 0.57 & 0.59 \\
\hline GBR & Reino Unido & 0.91 & 0.70 & 0.83 & 0.85 & 0.91 \\
USA & Estados Unidos & 1.00 & 1.00 & 0.67 & 0.91 & 0.92 \\
\hline
\end{tabular}

Elaboración propia.

En la tabla 5 se muestran los niveles de correlación entre los distintos modelos DEA. La máxima correlación positiva sería 1 (ambas variables crecen en la misma dirección), y la mínima 0 (no existe relación entre las variables). El índice de correlación podría ser -1 indicando que la correlación es negativa (al crecer una de las variables, la otra decrece en la misma proporción). Cuando la correlación entre dos modelos es cercana a 1, el comportamiento de ambos modelos será prácticamente el mismo. Analizando los 5 modelos DEA considerados, se observa que la correlación es especialmente alta (ver tabla 5) entre el modelo orientado a la eficiencia en la igualdad en el reparto de la renta y el modelo orientado a la eficiencia contra la pobreza $(0,98)$. También es alta la correlación entre el modelo orientado a la producción, por un lado, y los orientados a la igualdad y contra la pobreza, por el otro $(0,89)$. 
TABLA 5. Coeficientes de correlación entre los modelos9

\begin{tabular}{|c|c|c|c|c|c|}
\hline $\begin{array}{l}\text { Coeficientes } \\
\text { de correlación }\end{array}$ & $\begin{array}{c}\text { Modelo } \\
\text { Básico }\end{array}$ & $\begin{array}{c}\text { Eficiencia } \\
\text { orientada a } \\
\text { la producción }\end{array}$ & $\begin{array}{c}\text { Eficiencia } \\
\text { orientada a la } \\
\text { sostenibilidad } \\
\text { ambiental }\end{array}$ & $\begin{array}{l}\text { Eficiencia } \\
\text { orientada a } \\
\text { la equidad }\end{array}$ & $\begin{array}{l}\text { Eficiencia } \\
\text { contra la } \\
\text { pobreza }\end{array}$ \\
\hline Modelo Básico & 1.00 & 0.91 & 0.66 & 0.98 & 0.99 \\
\hline $\begin{array}{l}\text { Eficiencia orien- } \\
\text { tada a la produc- } \\
\text { ción }\end{array}$ & & 1.00 & 0.69 & 0.89 & 0.89 \\
\hline $\begin{array}{l}\text { Eficiencia orienta- } \\
\text { da a la sostenibili- } \\
\text { dad ambiental }\end{array}$ & & & 1.00 & 0.62 & 0.68 \\
\hline $\begin{array}{l}\text { Eficiencia orienta- } \\
\text { da a la equidad }\end{array}$ & & & & 1.00 & 0.98 \\
\hline $\begin{array}{l}\text { Eficiencia contra la } \\
\text { pobreza }\end{array}$ & & & & & 1.00 \\
\hline
\end{tabular}

Elaboración propia.

A partir de los resultados obtenidos por los 29 países seleccionados construimos una taxonomía de países utilizando los modelos DEA. El hecho de que haya una correlación alta entre tres de las variables (eficiencia orientada a la producción, eficiencia orientada a la igualdad y eficiencia orientada a la pobreza) hace que no podamos utilizarlas conjuntamente a la hora de "clusterizar"; por ello utilizamos las variables: eficiencia orientada a la sostenibilidad ambiental y eficiencia orientada a la igualdad, ya que la correlación entre estos dos modelos DEA es la más baja $(0,62)^{10}$. Para realizar esta taxonomía utilizamos la técnica del análisis "clúster". Esta técnica coloca en el mismo grupo a los individuos (en nuestro caso, los 29 países de la OCDE) que muestran características semejantes en las variables

9 El coeficiente de correlación habitualmente utilizado es el "coeficiente de Pearson". Este coeficiente nos muestra la relación entre dos variables. Oscila entre +1 y -1 . Un valor de +1 nos indica que al crecer una variable, la otra también crece en la misma proporción (están correlacionadas de forma positiva), un valor de -1 nos indica que al crecer una variable, la otra decrece en la misma proporción (están correlacionadas de forma negativa), y un valor 0 indicaría que las variables no tienen relación. Matemáticamente se puede definir como $\square_{v}=\operatorname{Cov}(x, y) / \square_{x} \square_{y}$, encontrándose en el numerador la covarianza de las variables y en el denominador las varianzas.

10 Se ha llevado a cabo un análisis One-way Multivariate Analysis of Variance (MANOVA), con el resultado $p=1.0 \mathrm{e}-005 \times[0.00000 .3954]^{\prime}$. 
consideradas, y coloca en grupos diferentes a los individuos (países de la OCDE) que muestran características diferenciadas ${ }^{11}$. Como resultado de este proceso de "clusterización" obtenemos 5 grupos. Los países ubicados en un mismo grupo comparten características en relación a las variables igualdad y sostenibilidad ambiental. Estas características son distintas en cada grupo (ver tabla 6).

En la figura 3 mostramos los cinco grupos ("clústeres"') en los que podemos agrupar los 29 países de la OCDE seleccionados, en función de las variables eficiencia orientada a la igualdad y eficiencia orientada a la sostenibilidad ambiental. El "clúster" 1 es el "clúster" que lidera los resultados tanto en términos de la eficiencia orientada a la igualdad, como de eficiencia orientada a la sostenibilidad ambiental. Los países ubicados en el "clúster" 1, con una misma dotación de "inputs", logran los mejores resultados en términos de sostenibilidad ambiental (el menor nivel de emisiones de $\mathrm{CO}_{2}$ por unidad de "output" y la tasa de reciclaje de residuos más alta) y también en términos de igualdad en el reparto de la renta (máxima equidad entre la población). Países como Dinamarca o Suecia pertenecen al grupo 1. Por el contrario, los países del grupo 5 presentan la media de eficiencia más baja en relación a la sostenibilidad ambiental y una posición muy baja en relación a la eficiencia en equidad. En este grupo podemos encontrar a muchos países del este de Europa, como Polonia o la República Checa. El resto de grupos o "clústeres" se encuentra en una posición intermedia entre los dos citados en relación a la eficiencia en igualdad y sostenibilidad ambiental. En el grupo 2, por ejemplo, encontramos países como Francia, Alemania, EEUU y otros, con unos resultados muy positivos en ambas dimensiones, ligeramente inferiores a los del grupo 1 . Los países del tercer "clúster" (Australia y Canadá) presentan un resultado muy positivo en la eficiencia orientada a la igualdad, si bien el resultado de la eficiencia orientada a la sostenibilidad ambiental es bajo. Finalmente, los países del grupo 4 (España, Portugal, Grecia, Italia y otros) presentan resultados mediocres en ambas dimensiones.

Si tomamos el conjunto de los resultados desde una perspectiva global, podemos constatar que existe una correlación positiva entre las tres dimensiones de la sostenibilidad (ver tablas 4 y 5 , y la figura 3). En la figura 3, el gráfico está midiendo simultáneamente la eficiencia desde el punto de vista de la sostenibilidad ambiental y desde el punto de vista de la equidad. Del análisis de este gráfico podemos concluir que las economías más avanzadas y desarrolladas no tienen que elegir entre ser eficientes en una dimensión de la sostenibilidad $\mathrm{u}$ otra: pueden conseguir ambos tipos de eficiencia al mismo tiempo (ver países en "clústeres" 1 y 2). Por otro lado,

${ }^{1}$ Se ha utilizado una clasificación jerárquica (aglomerativa) por el método de Ward. 
los países miembros de la $\mathrm{OCDE}$ en vías de desarrollo o en transición se encuentran en los "clústeres" 4 y 5 ; ambos son los únicos que presentan medias inferiores a las medias globales de los 29 países seleccionados. Si a esta situación le añadimos los datos relativos a la eficiencia orientada hacia la producción (generación de PIB "per cápita"), se torna más clara todavía la relación entre las tres dimensiones de la sostenibilidad. Mientras que las economías avanzadas y desarrolladas obtienen resultados de eficiencia más altos en las tres dimensiones de la sostenibilidad al mismo tiempo ("clústeres" 1 y 2), las economías en transición o en vías de desarrollo (localizadas principalmente en los "clústeres" 4 y 5 ) presentan niveles de eficiencia más bajos, especialmente en el modelo orientado a la producción. Tras este análisis podemos concluir que las tres dimensiones de la sostenibilidad están ligadas y, debido a esta situación, las economías más avanzadas y desarrolladas pueden progresar más rápidamente hacia la sostenibilidad social y ambiental (ver tablas 4 y 5 , y la figura 3).

FIGURA 3. Representación gráfica de los "clústeres"

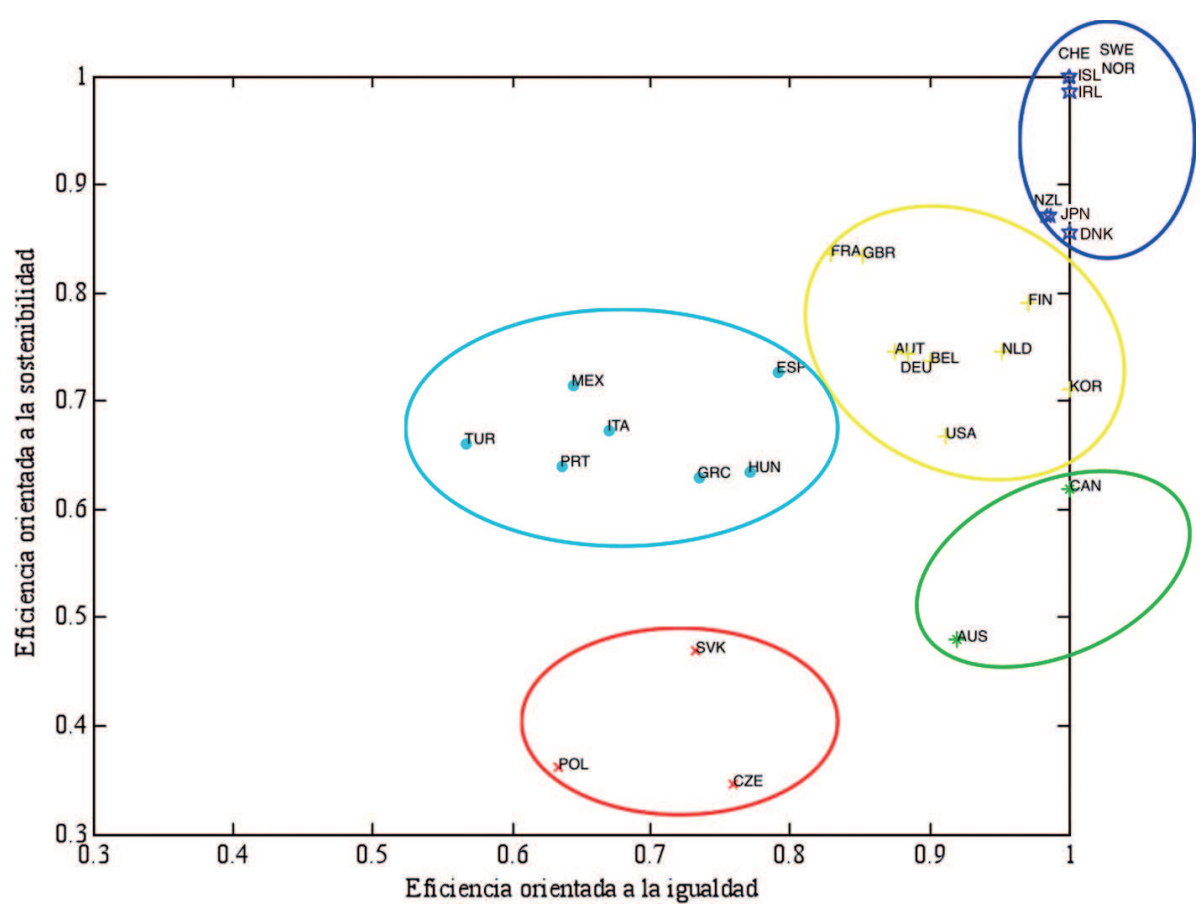

Elaboración propia. 
TABLA 6. Caracterización de los "clústeres"

\begin{tabular}{|c|c|c|}
\hline "cluster" & $\begin{array}{c}\text { Eficiencia sostenibilidad } \\
\text { ambiental }\end{array}$ & $\begin{array}{c}\text { Eficiencia orientada a la } \\
\text { equidad }\end{array}$ \\
\hline Media "cluster" 1 & 0.95 & 1.00 \\
\hline Media "cluster" 2 & 0.76 & 0.91 \\
\hline Media "cluster" 3 & 0.55 & 0.96 \\
\hline Media "cluster" 4 & 0.67 & 0.69 \\
\hline Media "cluster" 5 & 0.39 & 0.71 \\
\hline Media TOTAL & $\mathbf{0 . 7 4}$ & $\mathbf{0 . 8 6}$ \\
\hline
\end{tabular}

Elaboración propia.

TABLA 7. Distribución en “clústeres”

\begin{tabular}{|l|l|c|l|l|c|}
\hline \multicolumn{2}{|c|}{ DMU (país) } & "clúster" & \multicolumn{2}{c|}{ DMU (país) } & "clúster" \\
\hline AUS & Australia & 3 & KOR & Corea & 2 \\
\hline AUT & Austria & 2 & MEX & México & 4 \\
\hline BEL & Bélgica & 2 & NLD & Holanda & 2 \\
\hline CAN & Canadá & 3 & NZL & Nueva Zelanda & 1 \\
CZE & República Checa & 5 & NOR & Noruega & 1 \\
\hline DNK & Dinamarca & 1 & POL & Polonia & 5 \\
\hline FIN & Finlandia & 2 & PRT & Portugal & 4 \\
\hline FRA & Francia & 2 & SVK & Eslovaquia & 5 \\
\hline DEU & Alemania & 2 & ESP & España & 4 \\
\hline GRC & Grecia & 4 & SWE & Suecia & 1 \\
\hline HUN & Hungría & 4 & CHE & Suiza & 1 \\
ISL & Islandia & 1 & TUR & Turquía & 4 \\
\hline IRL & Irlanda & 1 & GBR & Gran Bretaña & 2 \\
\hline ITA & Italia & 4 & USA & Estados Unidos & 2 \\
\hline JPN & Japón & 1 & & &
\end{tabular}

Elaboración propia. 


\section{Conclusiones}

En este artículo hemos analizado el concepto de PIB y su relación con la sostenibilidad. La sostenibilidad cuenta con tres dimensiones principales (económica, social y ambiental), aunque el PIB no considera adecuadamente las dos últimas. Esto quiere decir que, por ejemplo, sería posible lograr un crecimiento de PIB positivo $y$, a la vez, presentar una tendencia negativa en cuanto a la sostenibilidad ambiental y social. Por estas razones, consideramos que el PIB es un instrumento incompleto para medir la sostenibilidad de una economía nacional, siendo adecuado complementarlo con otros indicadores para obtener una medición holística de las diversas dimensiones de la sostenibilidad. En la segunda parte de este artículo hemos procedido a seleccionar indicadores "input" $y$ "output" relacionados con las tres dimensiones de la sostenibilidad y, a partir de esos indicadores, hemos medido la eficiencia de 29 países de la OCDE a la hora de lograr un desarrollo sostenible mediante cinco modelos DEA diferentes. Los resultados varían de país en país, pero es posible agrupar esos 29 países en 5 "clústeres". En el "clúster" 5 se encuentran los países líderes en cuanto a eficiencia en equidad y cuidado ambiental, mientras que en el "clúster" 3 se localizan los países con resultados muy bajos en las dos dimensiones (social y ambiental). Los "clústeres" 1, 2, y 4 se encuentran en posiciones intermedias. Estos resultados muestran que es posible conseguir de manera simultánea sostenibilidad ambiental y social: no es necesario tener que elegir entre ellos. De hecho, estas dos dimensiones de la sostenibilidad están positivamente correlacionadas con el crecimiento del PIB, lo que implica que para las sociedades desarrolladas es más fácil "desacoplar" el crecimiento económico de las emisiones de $\mathrm{CO}_{2}$ y evitar situaciones de pobreza infantil y desigualdad extrema en el reparto de la renta. El Pensamiento Social Cristiano (PSC) comparte una concepción holística de la sostenibilidad, reconociendo las tres dimensiones de la misma: social, ambiental y económica. De hecho las encíclicas papales analizadas en este artículo son favorables a una justa distribución de la renta a nivel internacional y local, a una gobernanza global para asegurar la sostenibilidad ambiental y a un crecimiento económico que sirva para mejorar la situación de las personas en situación de pobreza. En otras palabras, lo que muchos economistas y el PSC están demandando es un verdadero desarrollo económico: un proceso de crecimiento económico que se preocupa de las personas y del medio ambiente, de manera que las generaciones presentes y futuras puedan vivir en un mundo más próspero, más justo y más ecológico. 


\section{Bibliografía}

AGUADO, R. (2010) "La competitividad sostenible: nuevo reto para las empresas y la sociedad": Boletín de Estudios Económicos n 200, (65), 263-282.

Arrow, K. J., Dasgupta, P., Goulder, L., Dally, G., Ehrlich, P. R., Heal, G. M., LeVIn, S. A., Mäler, K.-G., Scheider, S., Starret, D. A. y Walker, B. (2004) "Are we Consuming Too Much?": Journal of Economic Perspectives (18-1), 147-172.

Arrow, K. J., Dasgupta, P., Goulder, L., Mumford, K. y Oleson, K. (2007) "China, the US, and Sustainability: Perspectives Based on Comprehensive Wealth": Discussion Paper, Department of Economics, Stanford University, California.

Arrow, K. J., Dasgupta, P., Goulder, L., Mäler, K.-G. y Scheider, S. (2003a) "Evaluating Projects and Assessing Sustainable Development in Imperfect Economies": Environmental and Resource Economics (26-4), 647-685.

Arrow, K. J., Dasgupta, P., Goulder, L., Mäler, K.-G. y Scheider, S. (2003b) "The Genuine Saving Criterion and the Value of population": Economic Theory (21-2), 217-225.

Banker, R. D., Charnes, A. y Cooper, W. W. (1984) "Some Models for Estimating Technical and Scale Inefficiencies in Data Envelopment Analysis". Management Sciences (30-9), 1078-1092.

Benedicto XVI (2009) Caritas in veritate.

BYRON, W. (2010) "Applying the principles of Catholic Social Thought to education for business": Estudios empresariales (132).

Charnes, A., Cooper, W. W. y Rhodes, E. (1978) "Measuring Efficiency of Decision Making Units": European Journal of Operational Research (2), 325-331.

CMEPSP (2009) Report of the commission on the measurement of economic performance et social progress, 14 de septiembre (http://www.stiglitz-sen-fitoussi. fr/en/documents.htm)

Совв, С. у Совв, J. (1994) The Green National Product, Lanham (EE.UU.), University Press of America. 
COBB, J. Y DALY, H. (1989) For the common good, redirecting the economy toward community, the environment and a sustainable future, Boston, Beacon.

Coell, T., RaO, D. y Battese, G. (1998) An Introduction to Efficiency and Productivity Analysis, Boston, Kluwer.

Compañía de Jesús (1995) Congregación General 34.

- (2008) Congregación General 35.

Conferencia Episcopal de Canadá, Comisión de asuntos sociales (1995) The Environmental crisis: the place of the human being in the cosmos.

- (2003) You love all that exists... all things are Yours, God, love of life.

- (2008) Our relationship with the environment: the need for conversion.

Cooper, W., Seiford, L. M. y Tone, K. (22000) Data Envelopment Analysis, Massachusetts (EE.UU.), Kluwer Academic.

COOPER W., SEIFORD L. M. y ZHU J. (2004) Handbook on Data Envelopment Analysis. Boston, Springer (Kluwer Academic).

DASGUPTA, P. (2007) "Measuring Sustainable Development: Theory and Application": Asian Development Review (84-1), 1-10.

DASGUPTA, P. y K-G. MÄLeR (2000) "Net National Product, Wealth, and Social WellBeing": Environmental and Development Economics (5-1), 69-93.

FarelL, M. J. (1957) "The measurement of productive efficiency": J. R. Statist. Soc. A. (120), 253-281.

Fernández Franco, F. (2011) "Editorial": Promotio lustitiae (105).

Fleurbaey, M. (2009) "Beyond GDP: The Quest for a Measure of Social Welfare": Journal of Economic Literature (47-4), 1029-1075.

Hamilton, K. y Clemens, M. (1999) "Genuine Savings Rates in Developing Countries": World Bank Economic Review (13-2), 333-356. 
Hamilton, K. y LUTz, E. (1996) "Green National Accounts: Policy Uses and Empirical Experience": Environment Department Technical Paper (39), Washington, Banco Mundial.

JuAN XXIII (1963) Pacem in terris.

JuAN PABLO II (1981) Laborens exercens.

- (1987) Sollicitudo rei socialis.

- (1990) Paz con Dios creador, paz con toda la creación (Mensaje para la Jornada Mundial de la Paz).

- (1991) Centessimus annus.

- (1998) De la justicia de cada uno depende la paz para todos (Mensaje para la Jornada Mundial de la Paz).

KuzNETS, S. (1934) "National Income, 1929-1932" (NBER): National Income, 1929-1932, 1-12.

LEE, H-Y Y PARK Y-T (2005) "An International Comparison of R\&D Efficiency: DEA Approach": Asian Journal of Technology Innovation (13-2), 207-222.

LEÓN XIII (1891) Rerum novarum.

Martínez, J y Santacoloma, J. F. (2005) "Las predicciones sobre el crecimiento económico: posibilidad de un modelo operativo": Boletín de Estudios Económicos $\left(60, n^{\circ} 184\right) 87-118$.

MaRTínez, J. (2010) "El PIB (per cápita) como indicador de sostenibilidad": Boletín de Estudios Económicos, (65, n² 200), 283-308.

- (2011) "Crecimiento económico: una visión alternativa" en AgUADO, R. y SANTACOLOMA, J. (coords.) Economía y Humanismo Cristiano (Una visión alternativa de la actividad económica), Bilbao, Universidad de Deusto.

McCarthy, J. (2006) Catholic Social Teaching and Ecology Fact Sheet. [www. sjweb.info/sjs] 
NeUMAYER, E. (1999) Weak versus strong sustainability: exploring the limits of two opposing paradigms, Cheltenham, Edward Elgar.

Nordhaus, W. y ToBIN, D. (1973) "Is Growth Obsotete?", en The Measurement of Economic and Social Performance: Studies in Income and Wealth (38), ed. Milton Moss, 509-531.

OrganizAcIón de las NACIONES UnIDAs-ONU (2005) 2005 World Summit Outcome, Nueva York, ONU.

- (2010) Summit on the Millennium Development Goals, Nueva York, ONU.

Osberg, L. y Sharpe, A. (2002) "An index of economic well-being for selected countries": Review of Economic and Wealth (48-3), 291-316.

PABLO VI (1967) Populorum progressio.

Pío XI (1931) Quadragessimo anno.

REID, A. y MIEDZINSKY, M. (2008) Eco-innovation (Final report for sectoral innovation watch), Technopolis Group.

Santacoloma, J. y Aguado, R. (2011) (coords) Economía y Humanismo Cristiano (Una visión alternativa de la actividad económica), Bilbao, Univ. de Deusto.

SIIECCHIA, L. (2004) "Environment ethics from the perspectives of NEPA and Catholic Social Teaching: ecological guidance for the 21 st century": William and Mary Environ. Law and Policy Review (28-3), 659-798.

SMith, P. C. y Street, A. (2005) "Measuring the efficiency of public services: the limits of analysis": J. R. Statist. Soc. A. (168-2), 401-417.

Stigutz, J., Sen, A. y Fitoussi, J-P (2009) The Measurement of Economic Performance and Social Progress Revisited - Reflections and Overview, 16 de septiembre de 2009 (http://www.stiglitz-sen-fitoussi.fr/en/documents.htm).

TAlBeRTH, J. CobB, C. y SlatterY, N. (2007) The Genuine Progress Indicators 2006: a tool for sustainable development, Oakland (CA), Redefining Progress.

THANASSOULIS, E. (2001) Introduction to the Theory and Application of Data Envelopment Analysis, Dordrecht, Kluwer. 
WACKERNAGEL, M. y W. RESS (1995) Our ecological footprint: reducing human impact on the earth, New Society Publisher, Gabriola Island (BC), The New Catalyst Bioregional Series.

World Commission on Environment and Development (1987) From One Earth to One World: An Overview, Oxford, Oxford University. 


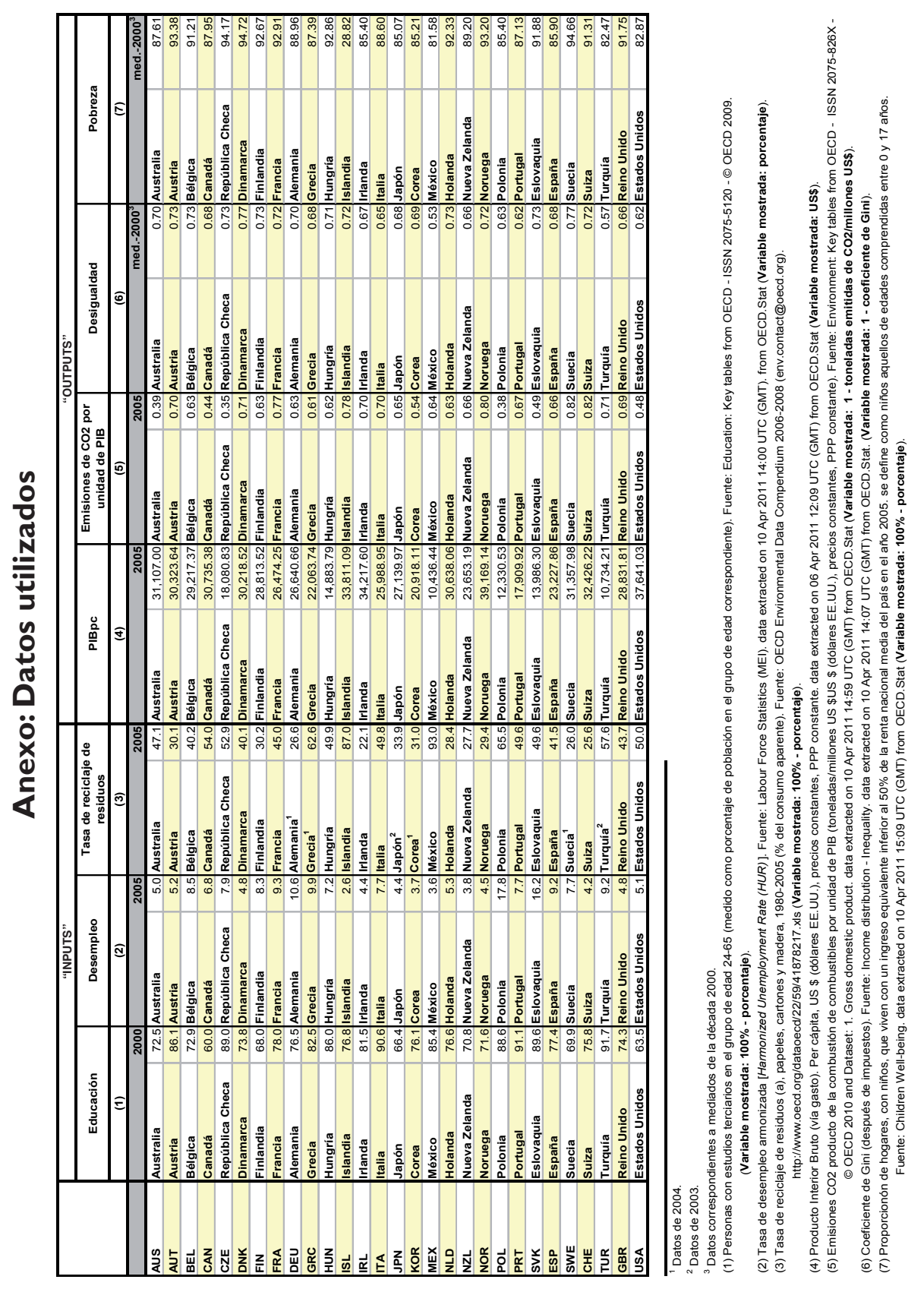

Revista de Fomento Social 66 (201I) 